Disponível em:

http://editora.unoesc.edu.br/index.php/race

RACE, Joaçaba, v. 16, n. 4, p. 261-282, jan./abr. 2017

\title{
ÍNDICE DE SUSTENTABILIDADE AMBIENTAL NA PRODUÇÃO LEITEIRA
}

Index of environmental sustainability in milk production

Daniela Di Domenico

E-mail: didomenico@unochapeco.edu.br

Mestre em Ciências Contábeis pela Universidade Regional de Blumenau; Graduada em Ciências Contábeis pela Universidade Comunitária da Região de Chapecó; Professora do Curso de Ciências Contábeis da Universidade Comunitária da Região de Chapecó.

Silvana Dalmutt Kruger

E-mail: silvanak@unochapeco.edu.br

Mestre em Ciências Contábeis pela Universidade Federal de Santa Catarina; Doutoranda em Ciências Contábeis na Universidade Federal de Santa Catarina; Professora do Curso de Ciências Contábeis da Universidade Comunitária da Região de Chapecó.

Sady Mazzioni

E-mail: sady@unochapeco.edu.br

Doutor em Ciências Contábeis e Administração pela Universidade Regional de Blumenau; Mestre em Ciências Contábeis pela Universidade Regional de Blumenau; Professor do Programa de Mestrado Acadêmico de Ciências Contábeis e Administração da Universidade Comunitária da Região de Chapecó.

Antonio Zanin

E-mail: zanin@unochapeco.edu.br

Doutor em Engenharia de Produção pela Universidade Federal do Rio Grande do Sul; Pós-doutorando na Universidade do Minho, Portugal, com o tema Avaliação de Desempenho em Cadeias de Suprimentos; Professor do Programa de Mestrado Acadêmico de Ciências Contábeis e Administração da Universidade Comunitária da Região de Chapecó. Endereço para contato: Avenida Senador Attílio Fontana, 591-E, 89809-000, Efapi, Chapecó, Santa Catarina, Brasil.

Michel Bruno Dalacorte Ludwig

E-mail: michelludwig_sb@unochapeco.edu.br Bacharel em Ciências Contábeis pela Universidade Comunitária da Região de Chapecó.

Artigo recebido em 31 de março de 2016. Aceito em 31 de outubro de 2016. 
Resumo

O objetivo com este estudo foi identificar o índice de sustentabilidade ambiental da atividade de produção leiteira em uma propriedade rural do Oeste de Santa Catarina. Para tanto, utilizouse o procedimento metodológico de um estudo de caso descritivo, com abordagem de cunho qualitativo. Os resultados da pesquisa evidenciam que entre os nove parâmetros do constructo utilizado, em oito deles a entidade rural pesquisada atende em $100 \%$ aos critérios estabelecidos. A exceção ocorreu quanto aos indicadores de destinação dos dejetos (armazenagem e destinação) e à diversidade de coberturas, em que não houve o atendimento das medidas. De forma geral, dos 100 pontos possíveis pelo modelo utilizado, a entidade rural atingiu 91\% dos critérios estabelecidos pela análise. Observou-se a necessidade de adequações no tratamento e destino final dos dejetos gerados pela produção leiteira, visando garantir, no longo prazo, melhorias para o meio ambiente. De modo geral, destaca-se a importância do controle e acompanhamento das práticas ambientais relacionadas à exploração econômica, visando à minimização do dano ambiental causado pela bovinocultura leiteira, permitindo que a atividade seja economicamente viável e ambientalmente correta.

Palavras-chave: Sustentabilidade ambiental. Produção leiteira. Indicadores.

\section{Abstract}

The aim of the study was to identify the environmental sustainability index of milk production activity in a rural property of the West of Santa Catarina. For this, we used the methodological procedure of a descriptive case study with a qualitative approach. The survey results show that among the nine parameters of the construct used, in eight of them the rural entity researched meets $100 \%$ the established criteria. The exception occurred on the indicators for allocation of waste (storage and disposal) and diversity of coverage, in which there was no compliance measures. Overall, of the 100 possible points by the model, the rural entity reached $91 \%$ of the criteria established by the analysis. There is a need for adjustments at the end of treatment and disposal of waste generated by dairy production to ensure long-term improvements to the environment. In general, it is worth highlighting the importance of controlling and monitoring the environmental practices related to economic exploitation, in order to minimize the environmental damage caused by dairy cattle, allowing activity to be economically viable and environmentally friendly.

Keywords: Environmental sustainability. Milk production. Indicators.

\section{INTRODUÇÃO}

A produção de leite está entre as atividades econômicas mais importantes no Estado de Santa Catarina, sendo uma das principais fontes de renda e empregos dire- 
tos e indiretos da região Oeste do Estado, a qual se difere do cenário nacional por ser desenvolvida em pequenas propriedades rurais de estrutura familiar (MIOR, 2007).

A cadeia produtiva do leite é considerada um dos principais segmentos do agronegócio, tanto do ponto de vista econômico quanto do ponto de vista social (VIANA; RINALDI, 2010). Muitas das pequenas propriedades rurais no Brasil possuem poucos animais e são administradas pelas próprias famílias, e o leite vem se tornando uma das principais fontes de renda da agricultura familiar (CARLOTTO; FILIPPI; MARCELLO, 2011).

O aperfeiçoamento da produção leiteira tem sido constatado em ritmo acelerado, a partir da melhoria no manejo do gado leiteiro com pastagens que se adaptam ao solo e ao clima, para maior rendimento da produção animal (CARLOTTO; FILIPPI; MARCELLO, 2011). Embora a produção leiteira se constitua em uma atividade econômica de importância para os pequenos produtores rurais, a preocupação com a sustentabilidade ambiental do processo produtivo passou a receber atenção e relevância.

O comprometimento com a sustentabilidade ocorre primeiramente com as mudanças na maneira de atuar nas atividades rurais, sendo necessária a conscientização de que a preservação deve prevalecer em primeiro plano, pois a natureza e os recursos ambientais oferecem as matérias necessárias para produzir, porém são finitos (BARBIERI et al., 2010).

Para tanto, é necessário também considerar os impactos ambientais do processo produtivo da atividade leiteira, para se observarem elementos e práticas que precisam ser melhorados, visando ao alcance da sustentabilidade ambiental dessa atividade. Kruger et al. (2015b) destacam a importância da avaliação de desempenho da sustentabilidade também para as cadeias produtivas agroindustriais, visando a melhores práticas produtivas e à minimização de impactos ambientais.

Nesse contexto, questiona-se: qual o nível do índice de sustentabilidade ambiental na atividade de produção leiteira? E tem-se por objetivo analisar o índice de sustentabilidade ambiental na atividade de produção leiteira em uma propriedade rural do Oeste catarinense.

O estudo justifica-se pela importância das atividades rurais no contexto socioeconômico, bem como pelo perfil das pequenas propriedades rurais do Oeste de Santa Catarina, que na maioria dos casos não permitem a agricultura totalmente mecanizável e são administradas pelas próprias famílias. O estudo justifica-se, ainda, pela relevância e necessidade da realização de estudos e pesquisas que considerem os aspectos da sustentabilidade para as práticas desenvolvidas no meio rural, tendo a 
agricultura como uma base fundamental para o desenvolvimento sustentável (MELO; CÂNDIDO, 2013).

As empresas de todo segmento, inclusive as entidades rurais, devem tomar consciência de seus atos e adotar uma postura responsável diante do meio ambiente, não somente para garantir sua competitividade, mas para agregar melhores práticas em relação à produção e ao manejo (PIZZORNO; UHLMANN; PFITSCHER, 2013).

A pesquisa encontra-se estruturada em outras quatro seções, além desta introdução. A segunda seção aborda a revisão da literatura, contemplando a contextualização da sustentabilidade ambiental, a atividade leiteira e estudos correlatos ao tema. Na terceira seção apresentam-se os procedimentos metodológicos utilizados para a realização da pesquisa, na quarta seção relatam-se os resultados da pesquisa e, finalmente, a quinta seção contempla as considerações finais do estudo.

\section{REVISÃO DA LITERATURA}

Nesta seção abordam-se o contexto da sustentabilidade ambiental e a importância da contabilidade para tal evidenciação e mensuração. Ainda, apresenta-se um breve contexto da exploração da produção leiteira.

\subsection{SUSTENTABILIDADE AMBIENTAL}

No ano 1983 foi criada pela Assembleia Geral da Organização das Nações Unidas (ONU) a Comissão Mundial sobre o Meio Ambiente e Desenvolvimento (CMMAD), sendo presidida por Gro Harlem Brundtland, na época Primeira-Ministra da Noruega. As discussões dos primeiros anos originaram, em 1987, o documento Our Common Future (Nosso Futuro Comum), também conhecido como Relatório Brundtland, em homenagem à presidente da comissão. O documento apresentou a incompatibilidade entre o desenvolvimento sustentável e os padrões de produção e consumo da época (BRASIL, 2015).

O relatório apresentou, ainda, o primeiro conceito sobre o desenvolvimento sustentável, considerado “[...] aquele que atende às necessidades do presente sem comprometer as possibilidades de as gerações futuras atenderem suas próprias necessidades.” (BARBOSA, 2008, p. 2).

Conforme Ferreira (1998, p. 12), “[...] o padrão de produção e consumo que caracteriza o atual estilo de desenvolvimento tende a consolidar-se no espaço das 
cidades e estas se tornam cada vez mais o foco principal na definição de estratégias e políticas de desenvolvimento.” Desse modo, é relevante a busca por alternativas sustentáveis que promovam a qualidade de vida para o processo de planejamento urbano.

Do ponto de vista empresarial, a sustentabilidade deve permitir a gestão dos recursos utilizados na produção, para que tragam retornos econômicos, sociais e ambientais, constituindo-se em um meio pelo qual uma empresa pode se manter atuante no mercado. Essa premissa é observada tanto no mercado financeiro internacional quanto no mercado financeiro nacional, em que os investidores têm privilegiado empresas socialmente responsáveis, sustentáveis e rentáveis para investir seus recursos (SILVA; QUELHAS, 2006).

A sustentabilidade consiste em “[...] assegurar o sucesso do negócio a longo prazo e ao mesmo tempo contribuir para o desenvolvimento econômico e social da comunidade, um meio ambiente saudável e uma sociedade estável.” (INSTITUTO ETHOS DE RESPONSABILIDADE EMPRESARIAL, 2001). Nesse aspecto, torna-se relevante a avaliação de indicadores de sustentabilidade, inclusive dessas iniciativas voltadas às práticas e às atividades rurais, no intuito de construir indicadores específicos que permitam aos gestores rurais avaliar de forma contínua o desempenho das atividades desenvolvidas (KRUGER et al., 2015b).

A Contabilidade, como fonte de informação sobre a contribuição da empresa ao desenvolvimento sustentável, pode coletar, analisar, mensurar e divulgar informações sobre a relação da empresa com o ambiente social, econômico e ecológico. Além disso, com as informações contábeis é possível estimarem-se os gastos e os resultados investidos com as ações de sustentabilidade, o que embasa as tomadas de decisões (BEBBINGTON; GRAY, 2001).

No contexto das propriedades rurais a contabilidade torna-se instrumento de apoio ao processo de planejamento e controle das atividades, permitindo analisar e comparar o desempenho econômico e financeiro e os custos por atividade desenvolvida, contribuindo com informações para o processo decisório (ZANIN et al., 2014). De acordo com Kruger et al. (2015a), a contabilidade rural fornece artefatos e informações para avaliar o desempenho econômico e financeiro das atividades rurais, bem como a viabilidade dos empreendimentos rurais.

O estudo de Sabbag e Costa (2015) destaca a importância do uso de indicadores de rentabilidade da produção leiteira, evidenciando a contabilidade como instrumento de apoio ao controle e planejamento das atividades. Nesse sentido, a contabilidade tornou-se indispensável para o desenvolvimento de práticas sustentáveis, e até mesmo para garantir a utilização dos recursos naturais, pois a viabilização ocorre 
perante os procedimentos que as instituições desempenham. As informações contábeis contribuem para a evidenciação das ações e práticas empresariais em prol do meio ambiente e da sociedade.

\subsection{ATIVIDADE LEITEIRA}

O Brasil apresentou um crescimento na produção leiteira de 14,65\% entre os anos 2010 e 2015 e no Estado de Santa Catarina o aumento foi de 48,61\% no mesmo período, de acordo com os dados do Instituto Cepa-Epagri (2016). Os dados do IBGE (2014) indicam que o Estado de Santa Catarina se tornou o quinto maior produtor de leite brasileiro, e a região Oeste é responsável por 70\% da produção estadual, onde a atividade tem se mostrado viável economicamente, inclusive em comparação com outras atividades econômicas.

Os fatores do crescimento da produção de leite no Oeste catarinense sustentam-se em dois indicadores: o número de vacas ordenhadas e a produtividade média da vaca em relação ao animal/ano. Para se chegar a esses índices é necessário ressaltar que fatores como alimentação e genética definem a qualidade do rebanho. Além de o custo da mão de obra ser menor, os modelos das pequenas propriedades favorecem a atividade e ainda oferecem os insumos para a produção, como fertilizadores naturais para o pasto (FISCHER et al., 2012).

Esses são alguns dos fatores que contribuem para o melhoramento e desenvolvimento da atividade. Além de contar com fatores climáticos e genéticos, a propriedade deve estar adequadamente instalada e disponibilizar mão de obra especializada, o que indica que a região Oeste de Santa Catarina tem grande potencial para esta atividade. Atualmente a bovinocultura leiteira é uma das principais atividades econômicas desenvolvidas na região (FISCHER et al., 2012).

A produção leiteira tem grande importância para o desenvolvimento econômico da região Oeste, além de contribuir para a permanência do homem no campo. Na sociedade a atividade leiteira é responsável por desempenhar um papel relevante, com a finalidade de suprir a necessidade de alimentos e contribuir para a geração de empregos (FISCHER et al., 2012).

A preocupação com os conceitos de sustentabilidade nas atividades agropecuárias tem sido abordada em outros estudos, a exemplo de Evangelista et al. (2006), Rempel et al. (2012), Barbosa et al. (2012), Melo e Cândido (2013), Zanin et al. (2014) e Kruger et al. (2015b). 
O estudo de Evangelista et al. (2006) elucida a identificação do setor produtivo da atividade leiteira, em termos de potencialidades e demandas da região Fronteira Noroeste do Rio Grande do Sul, diagnosticando e apontando processos orientados para a formação de uma cadeia produtiva para este segmento. De forma geral, os autores constataram que o sistema produtivo leiteiro na região é incipiente e carece de maior interação entre as instituições e a aplicação de procedimentos para transformá-lo em um sistema autossustentável.

A pesquisa de Rempel et al. (2012) apresentou uma proposta metodológica para a avaliação da sustentabilidade ambiental de propriedades produtoras de leite. A avaliação ambiental permite ao produtor rural averiguar processos da atividade que estejam em desconformidade com a sustentabilidade, visando proporcionar às propriedades uma unidade de medida objetiva de impacto, a qual auxilia na qualificação e certificação de propriedades agropecuárias.

Barbosa et al. (2012) destacam a importância do gerenciamento dos recursos e dos resultados das atividades desenvolvidas no meio rural, visando ao controle dos custos de produção e rentabilidade das atividades. A pesquisa ressalta a inexistência de um sistema de mensuração, acumulação e gerenciamento de custos, o que resultou em diferenças expressivas na rentabilidade das atividades analisadas. Além disso, evidenciam a necessidade da utilização e análise dos controles dos custos de produção.

Melo e Cândido (2013) avaliaram de forma comparativa os níveis de sustentabilidade existentes nos diferentes sistemas de manejo agrícola familiar, praticados no Município de Ceará-Mirim, RN. Para tanto, foram selecionadas 30 propriedades familiares, divididas em três grupos, de acordo com a sua forma de manejo: 10 propriedades “convencionais”, 10 “orgânicas” e 10 “agroecológicas”. Os resultados obtidos apontaram a dimensão "socioterritorial” como aquela que está limitando a sustentabilidade como um todo nos três grupos de propriedades estudadas. Eles também mostraram que, de forma geral, as propriedades orgânicas são as que apresentam o maior nível de sustentabilidade entre os três modelos produtivos avaliados no Município.

O estudo de Zanin et al. (2014) evidencia as fragilidades do uso de controles e da utilização da contabilidade no meio rural, tanto para a análise e o acompanhamento dos resultados quanto para o apoio ao processo decisório relacionado às atividades desenvolvidas no meio rural. A pesquisa de Kruger et al. (2015b) enfatiza a importância dos indicadores de desempenho e de sustentabilidade para o meio rural, como forma de avaliar de forma contínua as atividades desenvolvidas sob o enfoque econômico-financeiro, social e ambiental. 
De forma geral, destaca-se a importância da atividade leiteira no contexto da geração de empregos e renda para o meio rural, especialmente para o Estado de Santa Catarina e a região Oeste. Ressalta-se a relevância da utilização da contabilidade e de seus instrumentos para a análise do desempenho das atividades desenvolvidas no meio rural, inclusive para a gestão da sustentabilidade ambiental das atividades.

\section{PROCEDIMENTOS METOdOLÓGicos}

O estudo propõe uma análise do sistema produtivo leiteiro, que é desenvolvido em uma propriedade da Linha Santa Maria, do Município de São Bernardino, no Oeste catarinense. A propriedade possui uma área total de 27,5 hectares, com predominância da atividade leiteira, praticada com um rebanho da raça holandesa, com produção de 20.000 litros mensais que é revendida aos postos de coleta e laticínios da região.

A pesquisa quanto aos objetivos tem caráter descritivo, ao observar os fatos, fazer seu registro, em seguida analisá-los, classificá-los e, por fim, interpretá-los. Esse tipo de pesquisa procura descrever as características do fenômeno pesquisado, estabelecendo relações entre variáveis e utilizando pesquisa de campo para coleta de dados (GIL, 2008).

Quanto aos procedimentos, trata-se de um estudo de caso, que segundo Marconi e Lakatos (2010, p. 274), “[...] refere-se ao levantamento com mais profundidade de determinado caso ou grupo humano sob todos os seus aspectos.” O estudo foi realizado em uma propriedade rural, embasado na interpretação dos dados coletados nas entrevistas não estruturadas e nos documentos disponibilizados pelo proprietário.

A análise documental “[...] utiliza como suporte subsidiário a construção de diagnósticos de uma pesquisa, informações coletadas em documentos materiais escritos” (COLAUTO; BEUREN, 2004, p. 140), enquanto “[...] a entrevista não estruturada, também denominada por alguns autores de entrevista em profundidade, possibilita ao entrevistado a liberdade de desenvolver cada situação na direção que considera mais adequada.” (COLAUTO; BEUREN, 2004, p. 133).

Quanto à abordagem do problema, tem caráter qualitativo, que segundo Longaray e Beuren (2003, p. 92), “[...] na pesquisa qualitativa concebem-se análises mais profundas em relação ao fenômeno que está sendo estudado.” A coleta dos dados foi realizada por meio de entrevistas não estruturadas com o produtor leiteiro, sendo compostas por perguntas abertas e fechadas, no mês de janeiro de 2015, e os dados correspondem ao ano 2014. A análise dos dados foi realizada com auxílio do Sof- 
tware Excel, por meio da elaboração de tabela e gráfico. Com base nas informações recolhidas, os dados financeiros, econômicos e patrimoniais serviram de base para a realização dos procedimentos da gestão da propriedade.

Simultaneamente, foi aplicado o questionário para a determinação da sustentabilidade da propriedade; utilizou-se o constructo adaptado de Verona (2008), que considera as dimensões econômica, social e ambiental. A realização da avaliação da situação da sustentabilidade na propriedade está baseada nos parâmetros: dejetos, área de preservação permanente (APP), agrotóxicos e fertilizantes, reserva legal, água, declividade, erosão, queimadas e uso da terra, conforme se pode evidenciar na Tabela 1.

Tabela 1 - Parâmetros, subparâmetros e pontuação de avaliação da sustentabilidade ambiental (continua)

\begin{tabular}{|c|c|c|c|c|}
\hline Parâmetro & $\begin{array}{c}\text { Pontuação } \\
\text { máxima }\end{array}$ & Subparâmetros & & \\
\hline \multirow{15}{*}{ 1. Dejetos } & \multirow{15}{*}{30} & 1.1 Armazenamento de dejetos sólidos & & \\
\hline & & Estrumeira fechada e coberta & & 10 \\
\hline & & Estrumeira fechada e sem cobertura & & 7 \\
\hline & & Sem estrumeira & & 3 \\
\hline & & Liberação do dejeto próximo a curso hídrico & & 0 \\
\hline & & 1.2 Armazenamento do dejeto líquido & & \\
\hline & & Tratamento total do efluente gerado e posterior & & 10 \\
\hline & & $\begin{array}{l}\text { liberação em curso hidrico } \\
\text { Estrumeira fechada e coberta }\end{array}$ & & 7,5 \\
\hline & & Estrumeira fechada e sem cobertura & & 5 \\
\hline & & Sem estrumeira & & 2,5 \\
\hline & & Liberação do efluente próximo a curso hídrico & & 0 \\
\hline & & 1.3 Destinação do dejeto animal & & \\
\hline & & Aplicação balanceada e longe dos recursos hídricos & & 10 \\
\hline & & Aplicação conforme disponibilidade de dejeto & & 5 \\
\hline & & Aplicação do dejeto sem controle & & 0 \\
\hline \multirow{12}{*}{ 2. APP } & \multirow{12}{*}{15} & 2.1 Percentual de utilização das APPs & & \\
\hline & & $0 \%$ & 10 & \\
\hline & & 1 a $30 \%$ & 7,5 & \\
\hline & & 31 a $55 \%$ & 5 & \\
\hline & & 56 a $80 \%$ & 2,5 & \\
\hline & & 81 a $100 \%$ & 0 & \\
\hline & & 2.2 Uso predominante na APP & & \\
\hline & & Mata nativa & 5 & \\
\hline & & Culturas permanentes e mata exótica & 4 & \\
\hline & & Áreas de pastagem & 3 & \\
\hline & & Agricultura & 2 & \\
\hline & & Benfeitorias & 1 & \\
\hline
\end{tabular}




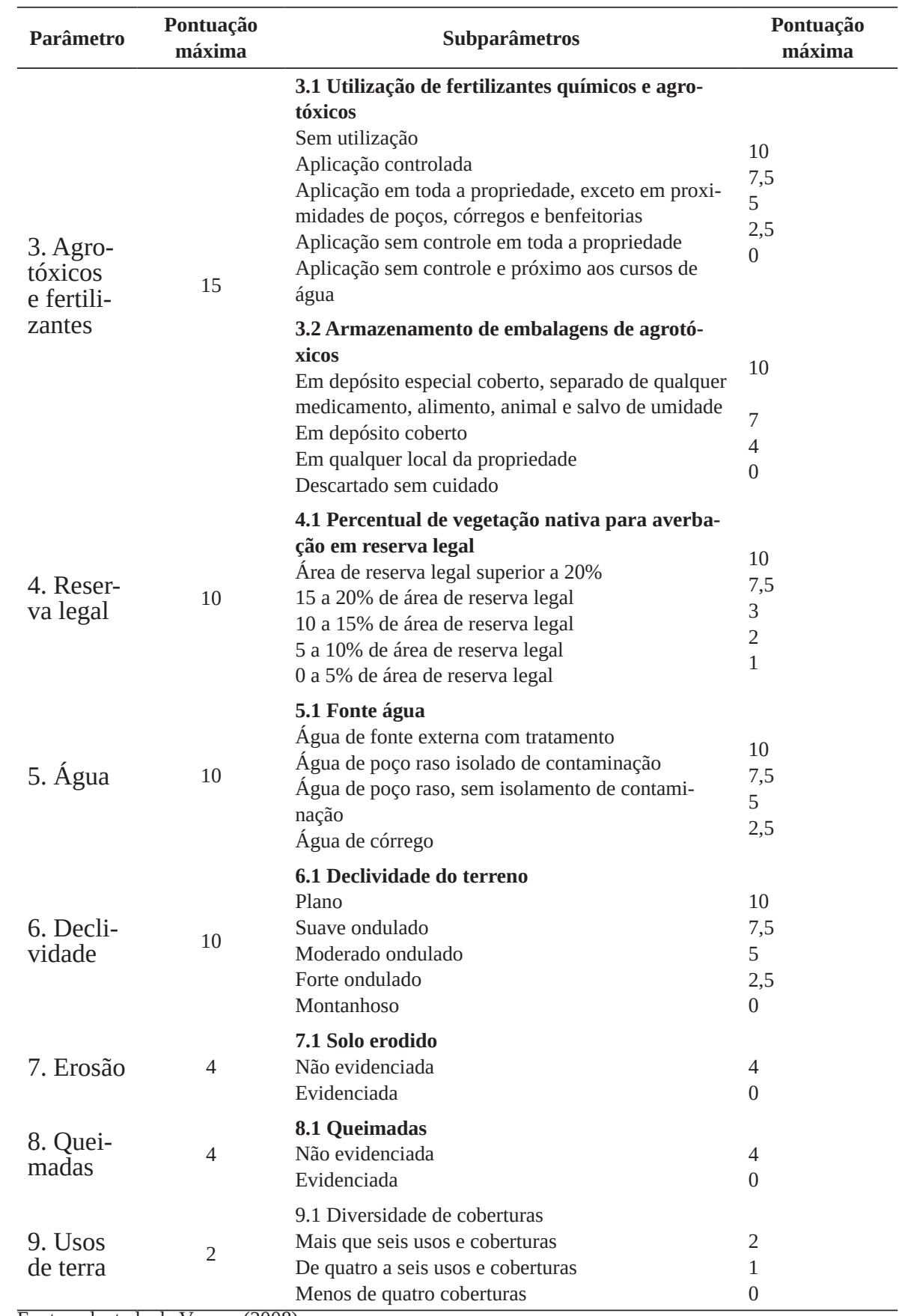

Fonte: adaptada de Verona (2008). 
Foi necessário eleger parâmetros dos itens estudados, assim como uma subdivisão de seus processos, para obter uma análise mais apropriada do sistema empregado na propriedade. Para a avaliação do parâmetro destinou-se uma pontuação máxima, seguida de um subparâmetro, classificado conforme a disposição da propriedade para a realização da atividade leiteira, em que a classificação possui pontuação entre 0 e 10 .

A partir da aplicação da pré-avaliação da sustentabilidade na propriedade leiteira, foi possível verificar que são necessárias etapas interdependentes as quais ocorrem de forma cronológica para a sua concretização. Realizaram-se visitas in loco para verificar a situação da propriedade em estudo e identificar o potencial da propriedade participante. As informações obtidas na unidade produtora serviram de suporte geral para as discussões com o produtor e para a avaliação inicial da área produtora.

Com base na metodologia apresentada na Tabela 1 , a pontuação máxima que uma propriedade leiteira pode alcançar é equivalente a 100 pontos no âmbito da sustentabilidade. Os dejetos produzidos pela produção leiteira compõem o indicador com maior peso, correspondendo a 30\% do total.

A atribuição da pontuação dentro de cada subparâmetro foi estabelecida considerando a melhor situação (maior pontuação) reduzindo na direção da pior situação (menor pontuação), com valores intermediários de acordo com o risco ou a exposição ao impacto ambiental. O Quadro 1 apresenta as situações possíveis de serem identificadas para os subparâmetros, os quais foram analisados e enquadrados conforme pontuação estabelecida na Tabela 1.

Quadro 1 - Conceito qualitativo da condição de sustentabilidade ambiental

\begin{tabular}{|l|l|}
\hline \multicolumn{1}{|c|}{ Índice de Sustentabilidade Ambiental } & \multicolumn{1}{|c|}{ Conceito } \\
\hline Pontuação igual ou maior a 0,80 & Excelente \\
Pontuação igual ou maior a 0,60 & Bom \\
Pontuação igual ou maior a 0,40 & Regular \\
Pontuação igual ou maior a 0,20 & Ruim \\
Pontuação menor que 0,20 & Inadequada \\
\hline Fonte: adaptado de Rempel et al. (2012).
\end{tabular}

O Quadro 1 apresenta o conceito que uma propriedade pode atingir, de acordo com o somatório da pontuação obtida nos parâmetros, pois é possível, por meio deles, estabelecer em qual categoria a unidade produtora de leite se encontra, de excelente à inadequada.

A classificação da propriedade é obtida por meio da pontuação do somatório dos parâmetros que se encontram na Tabela 1 . A realização de cada prática está vinculada com a soma dos subparâmetros que a propriedade atingiu, em seguida, realiza-se o 
somatório de todos os parâmetros. Depois de obtida a pontuação da unidade produtora, é realizada a divisão dos parâmetros por 100 (pontuação máxima que pode ser alcançada pela propriedade) para se obter o indicador de sustentabilidade da propriedade.

Com o índice obtido, é possível indicar o conceito qualitativo da questão sustentável encontrado na propriedade. Os índices de sustentabilidade da propriedade analisada foram avaliados em conjunto, objetivando a identificação das principais práticas e ações que expõem o risco da qualidade ambiental da unidade produtora leiteira.

\section{ANÁLISE E INTERPRETAÇÃO DOS RESULTADOS}

Nesta seção, apresentam-se as peculiaridades pertinentes à sustentabilidade e gestão da atividade de produção leiteira, visando atender ao objetivo da pesquisa e com o intuito de oferecer subsídios para melhorar o sistema produtivo da propriedade. Os resultados proporcionados pelo estudo também podem suprir as necessidades de informações aos produtores rurais para a tomada de decisões e realizar os processos produtivos de acordo com as práticas sustentáveis.

A partir dos dados coletados foi possível identificar o índice de sustentabilidade ambiental, baseado na avaliação da interação do sistema de produção com os principais componentes ambientais. A Tabela 2 apresenta os indicadores dentro de cada subparâmetro e a pontuação obtida na propriedade.

Tabela 2 - Pontuação e conceito de cada subparâmetro analisado

\begin{tabular}{|c|c|c|c|}
\hline Parâmetro & Subparâmetro & $\begin{array}{c}\text { Pontuação } \\
\text { propriedade }\end{array}$ & $\begin{array}{l}\text { Total parâ- } \\
\text { metro }\end{array}$ \\
\hline \multirow{3}{*}{ Dejetos } & Armazenamento do dejeto sólido & 7 & \multirow{3}{*}{24,5} \\
\hline & Armazenamento do dejeto líquido & 7,5 & \\
\hline & Destinação do dejeto animal & 10 & \\
\hline \multirow{2}{*}{ APP } & Percentual de utilização das APPs & 10 & \multirow{2}{*}{15} \\
\hline & Uso predominante na APP & 5 & \\
\hline Agrotóxicos e & Utilização de fertilizantes químicos e agrotóxicos & 5 & \multirow{2}{*}{15} \\
\hline fertilizantes & Armazenamento de embalagens de agrotóxicos & 10 & \\
\hline Reserva legal & $\begin{array}{l}\text { Percentual de vegetação nativa para averbação } \\
\text { em reserva legal }\end{array}$ & 10 & 10 \\
\hline Água & Fonte de água & 10 & 10 \\
\hline Declividade & Declividade do terreno & 7,5 & 7,5 \\
\hline Erosão & Evidências de solo erodido & 4 & 4 \\
\hline Queimadas & Evidências de queimadas & 4 & 4 \\
\hline Usos de terra & Diversidade de coberturas & 1 & 1 \\
\hline Total & & & 91 \\
\hline
\end{tabular}


A Tabela 2 apresenta parâmetros, subparâmetros e os indicadores de cada subparâmetro, as respectivas pontuações e conceitos obtidos pela propriedade, visando chegar ao índice de sustentabilidade. Para realizar a análise da sustentabilidade da propriedade, utilizaram-se os conceitos aplicados nos estudos de Verona (2008) e Rempel et al. (2012).

No primeiro item a propriedade apresenta a classificação do armazenamento de dejetos sólidos, que pode variar de 0 a 10 dependendo das condições de armazenagem que a propriedade disponibiliza. A melhor recomendação é a estrumeira fechada e coberta, que recebe a pontuação máxima.

O primeiro parâmetro de dejetos possui como primeiro subparâmetro a armazenagem dos dejetos sólidos produzidos, cuja pontuação obtida foi de 7 pontos, pois a propriedade possui a estrumeira fechada e sem cobertura. Na sequência, o subparâmetro sobre o armazenamento dos dejetos líquidos, para o qual a propriedade possui a estrumeira fechada e coberta e obteve a pontuação de 7,5 pontos. Por fim, o subparâmetro sobre a destinação dos dejetos animais, cuja aplicação balanceada e longe dos recursos hídricos obteve a pontuação máxima 10.

Assim, o total de pontos do parâmetro de dejetos ficou em 24,5. Esse parâmetro recebe muita importância, pois a destinação dos dejetos animais necessita de rigoroso controle para não contaminar os recursos hídricos da propriedade leiteira e as propriedades vizinhas, além das bacias leiteiras. Melo e Cândido (2013) também avaliaram de forma comparativa os níveis de sustentabilidade, destacando as especificidades entre os sistemas de manejo agrícola familiar, evidenciando a necessidade de melhorias na destinação de resíduos e dejetos.

O subparâmetro que diz respeito à área de preservação permanente (APP) trata de espaços protegidos, cobertos ou não por vegetação nativa, com a função ambiental de preservar os recursos hídricos, a paisagem, a estabilidade geológica, a biodiversidade, entre outros fatores. A melhor pontuação ficará com a área que possuir menor intervenção dos seres humanos, ou seja, aquela que o ser humano pouco modificou ou fez ajustes. Esse parâmetro possui dois subparâmetros, referentes ao percentual de utilização das APPs e ao uso predominante na APP. Em ambos os casos, a propriedade obteve a pontuação máxima de 10 e 5 pontos, respectivamente, por não utilizar as áreas de APP e possuir mata nativa.

O terceiro parâmetro é sobre o uso de agrotóxicos e fertilizantes, que analisou se a propriedade os utiliza e a forma de aplicação. No primeiro subparâmetro a propriedade estudada obteve 5 pontos pelo fato de que não aplica em proximidades de poços, córregos e benfeitorias. Já no segundo quesito, recebeu 10 pontos pela forma 
de armazenar as embalagens de agrotóxicos, visto que possui um depósito especial coberto, separado de qualquer medicamento, alimento ou animal e salvo de umidade.

Com a evolução da agricultura e da pecuária, tornou-se comum o uso de agrotóxicos para elevar a produtividade, porém o uso descontrolado e sem o devido acompanhamento técnico acaba gerando efeitos colaterais no processo de utilização. O desenvolvimento da agropecuária, de modo geral, tem contribuído para a poluição do solo e das águas. Fertilizantes químicos e agrotóxicos usados em quantidades abusivas nas lavouras poluem o solo e os recursos hídricos. Por esses e outros fatores, as propriedades que têm por intuito se adequar aos modos sustentáveis de produção devem estar atentas a esses quesitos. Nesse sentido, é necessário o uso moderado de fertilizantes químicos e agrotóxicos, respeitando as proximidades mínimas dos recursos hídricos.

O uso descontrolado de fertilizantes e de agrotóxicos torna-se uma prática negativa, potencializada pela destinação incorreta das embalagens e pela armazenagem inadequada, que geram a contaminação das áreas, partindo-se do pressuposto de que a armazenagem deve ser feita em depósito especial, coberto e separado de qualquer medicamento, alimento ou animal e salvo de umidade, sendo uma prática condenável o descarte das embalagens sem o mínimo cuidado.

O próximo parâmetro avaliado é a classificação da reserva legal, área dentro da propriedade rural que deve ser preservada pelo proprietário por abrigar parcela representativa do ambiente natural da região, tornando-se necessária para a manutenção da biodiversidade do local onde a unidade produtora está inserida. Nesse quesito, apresentam índices significativos aquelas propriedades que tiverem uma área superior a 20\% da área total para a reserva legal, e tendo uma péssima avaliação as que não atingirem o mínimo de 5\% da área total da propriedade. A propriedade investigada obteve 10 pontos, sendo conceituada como excelente, pois a área de preservação legal foi superior aos 20\% mínimos, enquadrando-se nos conceitos da reserva legal para a região da propriedade.

A água é um elemento da natureza indispensável à vida, sendo conceituada como o quinto subparâmetro. É um dos elementos que integram o meio ambiente natural e como tal recebe a proteção do Estado. Por esses e outros motivos se torna um indicador indispensável para a produção leiteira, aliado às demais questões sustentáveis.

Na atividade leiteira, a água está presente nos diversos processos produtivos, a exemplo da irrigação das lavouras, lavagem das benfeitorias, alimentação dos animais que consomem em média 30 litros diários, entre outros fatores. Então, para uma 
propriedade, é representativa a existência de um bom reservatório de água, viabilizado por meio do uso da água dos córregos, dos poços rasos, dos poços profundos ou até mesmo de sistemas de armazenamento de águas pluviais.

A pesquisa de Rempel et al. (2012) corrobora tais aspectos evidenciando a necessidade de os gestores rurais averiguarem os processos da produção leiteira que estejam em desconformidade com a sustentabilidade e de identificarem unidades de medidas que evidenciem fatores de impacto e alternativas para a melhoria desses aspectos ambientais, como o caso da água consumida pelas atividades rurais, do uso de fertilizantes e da contaminação do solo.

A propriedade estudada obteve 10 pontos pela utilização de água de fonte externa com tratamento. Além disso, pode-se inferir nesse parâmetro que na atividade leiteira o uso de água de melhor qualidade pode elevar a qualidade do produto final.

A análise da declividade do terreno constitui o sexto parâmetro. A agricultura e a pecuária representadas pela produção leiteira estão cada vez mais mecanizadas, condição adequada na utilização de terrenos planos ou mesmo daqueles suavemente ou moderadamente ondulados. A propriedade de estudo está localizada no Oeste catarinense, onde as condições geográficas apresentam acentuados níveis de declividade do terreno, o que resultou em uma conceituação boa, ou seja, 7,5 pontos. Mas o desenvolvimento da atividade nessas condições ainda é possível, diminuindo um pouco a produção por área, porém não intervindo na produtividade leiteira dos animais.

As erosões são decorrentes do mau uso dos solos e até mesmo das queimadas nas vegetações existentes. Esses quesitos formam o sétimo, o oitavo e o nono parâmetros e podem ser analisados de forma conjunta. A propriedade investigada não apresenta erosão, totalizando quatro pontos no sétimo parâmetro, não realiza queimadas no solo, obtendo quatro pontos, e faz a cobertura de solos além da rotação de culturas, obtendo um ponto.

Porém, conforme mencionado anteriormente, a declividade interfere na produção. Desse modo, as propriedades rurais da região, normalmente, disponibilizam somente pequenas quantidades de terra, fazendo com que a rotação de culturas não seja a mais correta possível, mas por meio de algumas técnicas é possível uma boa produção e conceituação da propriedade. Além disso, o uso de queimadas está extinto na propriedade, o que favorece o solo, pois nos períodos de entressafra o terreno não fica exposto às chuvas, eliminando, assim, as erosões.

As plantas de cobertura dos solos têm por finalidade proteger o solo contra os impactos das gotas de chuva, resultando, assim, na diminuição do risco de erosão e tornando o ambiente mais propício para que haja ciclagem dos nutrientes na área. 
Ainda, impedem a perda de nutrientes, contribuem para a manutenção e melhoram os atributos físicos, químicos e biológicos do solo.

Em linhas gerais, na propriedade foram avaliados nove parâmetros, com seus devidos subparâmetros, cuja análise pelos parâmetros da Tabela 2 gerou um índice de sustentabilidade à propriedade de 0,91. De acordo com as premissas do Quadro 1, a propriedade obteve o conceito “Excelente”, indicando uma boa aplicabilidade de práticas sustentáveis na propriedade.

Para melhor visualização, a Figura 1 apresenta os índices sustentáveis da propriedade estudada, de cada parâmetro. O tracejado azul representa o máximo de pontuação que a propriedade poderia atingir dentro do modelo utilizado. Em cor laranja, tem-se o resultado obtido pela propriedade, que demonstra o bom enquadramento da unidade produtora de leite, nos parâmetros e subparâmetros da sustentabilidade.

Figura 1 - Desempenho dos indicadores ambientais avaliados na propriedade leiteira analisada

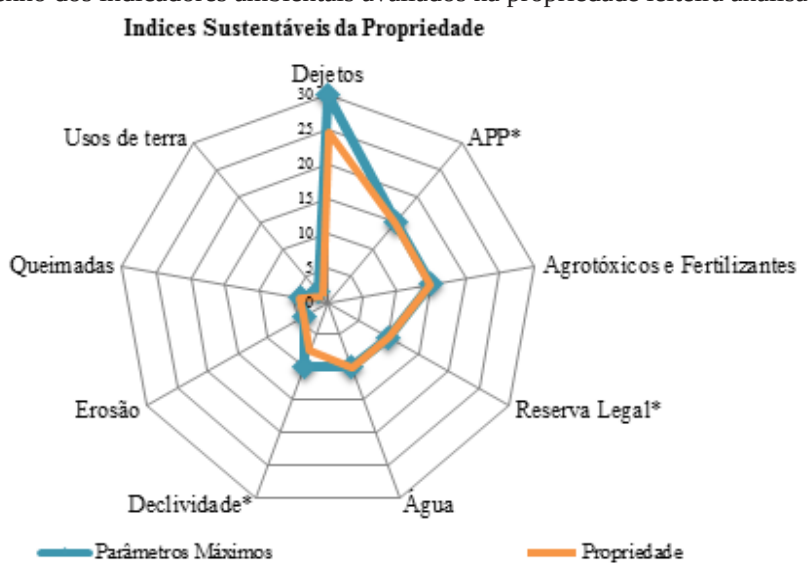

Fonte: os autores.

É possível visualizar, por meio da Figura 1, o nível de conformidade dos nove indicadores ambientais avaliados na propriedade leiteira em relação ao modelo teórico utilizado. Os itens com maior destaque pela sua conformidade são a reserva legal, o uso de agrotóxicos e a utilização da água. O indicador mais bem avaliado foi a reserva legal, em que a propriedade apresentou qualidade ambiental, retratada pelas práticas associadas à atividade leiteira e à agricultura consorciada. Porém, a propriedade apresentou limitações, principalmente em razão da utilização da terra (em decorrência da declividade característica das propriedades do Oeste catarinense) e do manejo de dejetos (que poderia ter um tratamento mais adequado). 
Para que a produção de leite se torne sustentável, é indispensável que ele receba assistência técnica, visando orientar a nortear o conjunto de decisões e normas técnicas aplicadas aos fatores produtivos (trabalho, terra e capital) e exigindo dos produtores rurais preparo técnico e gestão dos processos produtivos, além de boas práticas ambientais (SILVA et al., 2015). Barbosa et al. (2012) também destacam a importância do gerenciamento dos recursos naturais relacionados à exploração das atividades desenvolvidas no meio rural.

No que se refere aos dejetos, a propriedade não obteve pontuação máxima, mas está de acordo com os índices sustentáveis. As instalações poderão ser adequadas, aprimorando a qualidade das estrumeiras, a partir de um planejamento de demanda dos recursos financeiros exigidos para o investimento. Por meio do modelo utilizado, constatou-se que os resultados obtidos estão em consonância com os índices de sustentabilidade ambiental esperados.

Os resultados corroboram o estudo de Kruger et al. (2015b), destacando a importância da avaliação de indicadores de sustentabilidade específicos para a análise das atividades rurais, visando ao acompanhamento e à melhoria contínua do desempenho sustentável das atividades desenvolvidas no meio rural.

\section{CONCLUSÃO}

Atualmente se constatam diversas mudanças nos ambientes produtivos, e a tecnologia auxilia no aprimoramento dessas práticas, exigindo que as propriedades leiteiras se adaptem aos novos padrões ambientais. Uma dessas mudanças é proporcionada pelo mercado consumidor, as pessoas desejam qualidade, porém não dispensam que os processos para tornar esse produto melhor estejam de acordo com as normativas e se utilizem dos preceitos da sustentabilidade ambiental para o processo produtivo.

A atividade leiteira vem crescendo no Brasil, em Santa Catarina e principalmente no Oeste catarinense, o que tem exigido dos produtores adaptação a novos processos produtivos, com a diminuição de custos e maior lucratividade por área, sendo indispensável a adoção das práticas sustentáveis.

Buscou-se demonstrar, a partir de um modelo teórico prévio, a sustentabilidade ambiental na produção leiteira de uma propriedade rural, utilizando-se de entrevistas com o produtor rural. O aprimoramento do processo produtivo na pecuária leiteira é importante para o agronegócio e mais relevante ainda para a economia familiar. Porém, o processo de remodelar o modo produtivo requer que todo o setor esteja en- 
volvido para que as ações sejam tomadas no âmbito coletivo tornando-se viáveis para a estruturação do sistema, que deverá ser feita coletivamente por parte do Governo, associações, cooperativas e, sobretudo, do produtor.

A análise do estudo permitiu identificar que dos 100 pontos possíveis pelo modelo utilizado, a entidade rural atingiu 91\% dos critérios estabelecidos pela análise. Observou-se que os elementos de conformidade são a reserva legal, o uso de agrotóxicos e a utilização da água, sendo a reserva legal o indicador mais bem avaliado, em decorrência das práticas associadas à atividade leiteira e à agricultura consorciada. Porém, o manejo dos dejetos ainda precisa receber tratamento adequado, visando à minimização dos impactos ambientais.

A atividade leiteira tem um importante papel na sustentabilidade ambiental, exigindo maiores investimentos a respeito da preservação do meio ambiente com auxílio técnico, financeiro e social dos órgãos governamentais e demais responsáveis. Deve-se persistir na redução do dano ambiental causado pela bovinocultura leiteira, permitindo que a atividade seja um negócio economicamente viável e ambientalmente adequado.

Por fim, pode-se afirmar que a sustentabilidade é importante para a produção leiteira a fim de melhorar todos os parâmetros produtivos da propriedade. O desenvolvimento sustentável da atividade leiteira também deve procurar atender às necessidades do presente sem comprometer a possibilidade de serem atendidas no futuro. $\mathrm{O}$ modelo utilizado permite avaliar as práticas adotadas pelos produtores rurais, permitindo tomar decisões a partir de argumentos mais sensatos, visando à implementação contínua de práticas adequadas em prol da sustentabilidade da produção leiteira.

Recomenda-se para estudos futuros o uso de pesquisa de levantamento em diversas propriedades rurais, permitindo a comparabilidade de resultados entre os diversos tipos de produtores, ponderando o tamanho das propriedades rurais e comparando outras características entre as atividades econômicas desenvolvidas.

\section{REFERÊNCIAS}

BARBIERI, J. C. et al. Inovação e sustentabilidade: novos modelos e proposições. Revista de Administração de Empresas - RAE, v. 50, n. 2, p. 146-154, 2010.

BARBOSA, G. S. O desafio do desenvolvimento sustentável. Revista Visões, v. 1, n. 4, p. 1-11, 2008.

BARBOSA, L. P. et al. Contabilidade, Gestão de Custos e Resultados no Agronegócio: Um estudo de caso no Rio Grande do Sul. In: CONGRESSO BRASILEIRO DE CUSTOS, 19., 2012, Bento Gonçalves. Anais... Bento Gonçalves: CBC, 2012. 
BEBBINGTON, J.; GRAY, R. An account of sustainability: failure, success and a reconceptualization. Critical Perspectives on Accounting, v. 12, i. 5, p. 557-588, 2001.

BRASIL. Acordos Globais. 2015. Disponível em: <http://www.brasil.gov.br/meio-ambiente/2012/01/acordos-globais>. Acesso em: 03 set. 2015.

CARLOTTO, I.; FILIPPI, A. J.; MARCELLO, E. I. Estudo de viabilidade da produção de leite em uma propriedade familiar rural do município de Francisco Beltrão-PR. Revista Ciências Empresariais UNIPAR, v. 12, n. 1, p. 95- 109, 2011.

COLAUTO, R. D.; BEUREN, I. M. Coleta, análise e interpretação dos dados. In: BEUREN, I. M. (Org.). Como elaborar trabalhos monográficos em contabilidade: teoria e prática. 3. ed. São Paulo: Atlas, 2004.

EMPRESA DE PESQUISA AGROPECUÁRIA E EXTENSÃO RURAL DE SANTA CATARINA. 2016. Disponível em: < http://www.epagri.sc.gov.br/?page_ id=2623 $>$. Acesso em: 31 mar. 2016.

EVANGELISTA, M. L. A. et al. A atividade leiteira como alternativa de geração e inclusão de capital social no contexto de pequenos produtores da Região Fronteira Noroeste do Rio Grande do Sul. In: SEMINÁRIO INTERNACIONAL SOBRE O DESENVOLVIMENTO REGIONAL, 3., 2006. Santa Cruz-RS. Anais... Santa Cruz: 2006.

FERREIRA, L. C. A questão ambiental: sustentabilidade e políticas públicas no Brasil. São Paulo: Boitempo Editorial, 1998. Disponível em: <http://www.scielo.br/ pdf/asoc/n5/n5a17.pdf>. Acesso em: 30 abr. 2014.

FISCHER, A. et al. Produção e produtividade de leite do Oeste catarinense. Revista de Administração, Contabilidade e Economia, v. 10, n. 2, p. 337-362, 2012.

GIL, A. C. Como elaborar projetos de pesquisa. São Paulo: Atlas, 2008.

INSTITUTO ETHOS DE RESPONSABILIDADE EMPRESARIAL. Responsabilidade Social. 2001. Disponível em: <http:// www.ethos.org.br>. Acesso em: 18 ago. 2015.

INSTITUTO BRASILEIRO DE GEOGRAFIA E ESTATÍSTICA DA PRODUÇÃO PECUÁRIA. 2014. Disponível em: <http://www.epagri.sc.gov.br/?page_id=2623>. Acesso em: 13 out. 2014. 
KRUGER, S. D. et al. Análise dos resultados da atividade leiteira: custo histórico versus valor justo dos ativos biológicos. Revista Extensão Rural, v. 22, n. 3, p. 6888, 2015 a.

KRUGER, S. D. et al. Avaliação de desempenho da sustentabilidade da produção suinícola: mapeamento internacional sobre o tema. Custos e @gronegócio on line, v. 11, n. 4, p. 124-153, 2015 b.

LONGARAY, A. A.; BEUREN, I. M. Trajetória da construção de um trabalho monográfico em contabilidade. In: BEUREN, I. M. (Org.). Como elaborar trabalhos monográficos em contabilidade: teoria e prática. 3. ed. São Paulo: Atlas, 2004.

MARCONI, M. A.; LAKATOS, E. M. Fundamentos de metodologia científica. 7. ed. São Paulo: Atlas, 2010.

MELO, L. E. L.; CÂNDIDO, G. A. O uso do método IDEA na avaliação de sustentabilidade da agricultura familiar no município de Ceará-Mirim - RN. Revista de Administração, Contabilidade e Sustentabilidade, v. 3, n. 2, p. 1-19, 2013.

MIOR, L. C. Agricultura familiar, agroindústria e desenvolvimento territorial. In: COLÓQUIO INTERNACIONAL DE DESENVOLVIMENTO RURAL SUSTENTÁVEL, 1., 2007, Florianópolis. Anais... 2007. v. 22.

PIZZORNO, C. E. A.; UHLMANN, V. O.; PFITSCHER, E. D. Sustentabilidade ambiental no contexto hospitalar: estudo em um hospital do Rio Grande do Sul. Revista de Administração Hospitalar e Inovação em Saúde, v. 10, n. 3, p. 1-16, 2013.

REMPEL, C. et al. Proposta metodológica de avaliação da sustentabilidade ambiental de propriedades produtoras de leite. Tecno-Lógica, v. 16, n. 1, p. 48-55, 2012.

SABBAG, O. J.; COSTA, S. M. A. L. Análise de custos da produção de leite: aplicação do método de Monte Carlo. Extensão Rural, v. 22, n. 1, p. 125-145, 2015.

SILVA, L. S. A.; QUELHAS, O. L. G. Sustentabilidade empresarial e o impacto no custo de capital próprio das empresas de capital aberto. Gestão \& Produção, v. 13, n. 3, p. 385-395, 2006.

SILVA, M. F. D. et al. Avaliação dos indicadores zootécnicos e econômicos em sistemas de produção de leite. Revista de Política Agrícola, v. 24, n. 1, p. 62-73, 2015. 
VERONA, L. A. F. Avaliação de sustentabilidade em agroecossistemas de base familiar e em transição agroecológica na região sul do Rio Grande do Sul. 2008. Tese (Doutorado em Agronomia)-Universidade Federal de Pelotas, 2008.

VIANA, G.; RINALDI, R. N. Principais fatores que influenciam o desempenho da cadeia produtiva de leite - um estudo com os produtores de leite do Município de Laranjeiras do Sul-PR. Revista Organizações Rurais \& Agroindustriais, v. 12, n. 2, p. 263-274, 2010.

ZANIN, A. et al. Gestão das propriedades rurais do oeste de Santa Catarina: as fragilidades da estrutura organizacional e a necessidade do uso de controles contábeis. Revista Catarinense da Ciência Contábil - CRCSC, v. 13, n. 40, p. 9-19, 2014.

\section{Como citar este artigo:}

ABNT

DI DOMENICO, Daniela et al. Índice de sustentabilidade ambiental na produção leiteira. RACE, Revista de Administração, Contabilidade e Economia, Joaçaba: Ed. Unoesc, v. 16, n. 1, p. 261-282, jan./abr. 2017. Disponível em: <http://editora. unoesc.edu.br/index.php/race>. Acesso em: dia/mês/ano.

APA

Di Domenico, D., Kruger, S. D., Mazzioni, S., Zanin, A., \& Ludwig, M. B. D. (2017). Índice de sustentabilidade ambiental na produção leiteira. RACE, Revista de Administração, Contabilidade e Economia, 16(1), 261-282. Recuperado em dia/mês/ ano, de http://editora.unoesc.edu.br/index.php/race 
